\title{
LOCAL DELIVERY OF TETRACYCLINE GROUP OF DRUGS AS ADJUNCTS TO MECHANICAL DEBRIDEMENT IN PERI-IMPLANTITIS: A SYSTEMATIC REVIEW AND META-ANALYSIS
}

\author{
Sunaina Banu', Pratibha G. ${ }^{1}$, Rajeshwari H.R. ${ }^{1}$, Ravishankar N. ${ }^{2}$ \\ 'Department of Periodontology, Manipal College of Dental Sciences, Manipal, Manipal Academy of Higher Education (MAHE), India \\ 2Department of Data Science, Prasanna School of Public Health, Manipal Academy of Higher Education (MAHE), Manipal, India
}

\begin{abstract}
Peri-implantitis is associated with bone loss around a dental implant. Apart from mechanical factors, microbial etiology with gram-negative anaerobic infection is implied. The condition can have a favorable prognosis with timely control of infection, implant surface detoxification, and bone regeneration. Further, since it is site-specific, there is a potential for targeted form of antimicrobial therapy. Tetracycline has been the conventional choice for local delivery agents. The present review systematically assessed the randomized and controlled clinical trials, evaluating the efficacy of local delivery of the tetracycline group of drugs adjunctive to non-surgical peri-implant debridement in the management of mild to moderate cases of peri-implantitis. We explored databases of PubMed, Cochrane Library, and Scopus electronically to include research papers published in English till the end of May 2019. In the first stage of assortment, we screened titles and abstracts and in the second stage, the selected papers were evaluated independently by three reviewers. From the initial search, we included 810 related titles and abstracts. Around seven articles were selected for rigorous evaluation after screening. Finally, only three papers met the inclusion criteria and were selected for the final review and meta-analysis. Based on our analysis, we found scant evidence to support the tetracycline group of drugs in mild to moderate peri-implantitis. Research in this area is limited and warrants further investigation through longitudinal, randomized, and controlled clinical trials.
\end{abstract}

KEY WORDS: antimicrobials, local drug delivery, peri-implantitis, systematic review, tetracyclines.

J Stoma 2021; 74, 2: 124-131

DOI: https://doi.org/10.5114/jos.2021.106679

\section{INTRODUCTION}

Dental implants have emerged as the preferred treatmentmodality for the rehabilitation of partialor completely edentulous patients. The popularity of dental implants may be credited to a high survival rate of about $82.94 \%$, seen up to 16 years [1]. However, there is increasing evidence of implant failures. Peri-implantitis is a common cause of implant-failure [2], i.e., failure of the implant to fulfil its purpose (functional, esthetic, or phonetic), because of mechanical or biological reasons [3]. Failure of dental implants attributed to peri-implant inflammation is often due to microbial colonies, imbalanced occlusal forces, oral abusive habits, such as bruxism, smoking, inferior quality of bone, implant thread design, post-surgical and prosthetic complications, and uncontrolled systemic diseases, like diabetes. The term "periimplantitis", first introduced by Mombelli in 1987 [4],
JOURNAL OF STOMATOLOGY CZASOPISMO STOMATOLOGICZNE
Address for correspondence: Prof. Pratibha Gopalkrishna, Department of Periodontology, Manipal College of Dental Sciences, Madhavnagar, Manipal, Manipal Academy of Higher Education (MAHE), Udupi District, Karnataka, India - 576104, e-mail: pratibha.pk@manipal.edu ReCeived: 10.02.2021 • ACCEPTED: 10.05.2021 • Published: 04.06.2021 
describes an inflammatory process affecting soft and hard tissues around a functioning osseointegrated implant, resulting in loss of supporting bone [5].

The use of an adjunctive agent for mechanical debridement is necessary, as the microbial biofilm plays a crucial role in the progression of peri-implantitis [6]. Epithelial cells have a continuous turnover, thereby inhibiting the binding and settlement of pathogenic microbes; however, the tooth/implant provides a non-shedding superficial layer remaining constant during life with no turnover, causing adherence of pathogens, including Porphyromonas gingivalis, Prevotella intermedia, Fusobacterium nucleatum, Treponema denticola, Aggregatibacter actinomycetemcomitans, etc.) [7, 8].

Although the literature on treatment modalities for peri-implantitis is abundant, substantial evidence supporting clinical decision-making is lacking [9]. Due to technical complications in decontaminating dental implant surfaces, eradicating tissue penetrating microorganisms becomes difficult, especially through mechanical debridement. Moreover, there were speculations regarding the use of supportive antimicrobial mechanisms for treating peri-implant infections during the late 90s $[10,11]$.

Systemic antimicrobial agents have shown beneficial effects, but in high dosages and in cases of generalized periodontal diseases. However, in confined conditions, such as peri-implantitis, the local delivery form of appropriate antimicrobial agents, delivered in small quantities, becomes more meaningful, as increased drug concentrations are possible at the site with minor side effects. The precise placement of implant into the affected pocket, along with prolonged action over several days and the possibility of penetration into the subgingival biofilm, enable predictable bacterial eradication [12].

Reported by Dr Max Goodson in 1979, a notion of local delivery of beneficial drugs has developed into a practical concept of periodontal disease management [13]. Various antimicrobial agents have been used in a local drug delivery mode for the treatment of chronic periodontitis and peri-implantitis $[14,15]$. A recent systematic review on periodontitis has shown agreeable results; however, there is no data for peri-implantitis. Therefore, its application for peri-implant disease condition needs additional investigation [16]. The present systematic review attempted to screen the available literature to fill up this gap in knowledge regarding management of periimplantitis using local drug delivery. Therefore, this systematic review aimed to focus on randomized controlled clinical trials evaluating the efficacy of tetracycline group of drugs used in local delivery formulation for treating early to moderate peri-implantitis cases, along with non-surgical, mechanical implant debridement.

\section{MATERIAL AND METHODS}

The present systematic review followed the guidelines of PRISMA statement. It is registered in PROSPERO, with registration No. CRD42019133291. The main question for the literature search was created based on PICO format [17]: "What is the clinical efficacy of the tetracycline group of drugs as a local drug delivery (LDD), when used as an adjuvant to non-surgical implant debridement in patients with early to moderate periimplantitis?" (Table 1).

\section{SEARCH STRATEGY}

PubMed, US National Library of Medicine, Cochrane Library (central) of the Cochrane Collaboration, and Scopus databases were selected to systematically search all possible answers on the question of interest. This was followed by reviewing research papers available in English, which included randomized controlled clinical trials, and published till the end of May 2019. The key terms and words used for the search were as follows: "peri-implantitis" or "periimplantitis" or "periimplantation", "local drug delivery" or "ldd" or "targeted drug delivery" as well as tetracyclines, doxycycline, minocycline, antimicrobials, and antibiotics. In PubMed ("tetracycline" [mesh terms] or "tetracycline" [all fields]) and local [all fields] and ("drug delivery systems" [mesh terms] or \{ "drug" [all fields] and "delivery" [all fields] and "systems" [all fields]\} or "drug delivery systems" [all fields] or \{ "drug" [all fields] and "delivery" [all fields]\} or "drug delivery" [all fields] and \{"peri-implantitis" [mesh terms] or "peri-implantitis" [all fields] or "periimplantitis" [all fields] were used. Human studies till the end of May 2019 (electronic and paper journals), in which "peri-implant" pocket depth (using a standard graduated probe), "bleeding", and "soft tissue inflammation" assessed with standard indices, were included.

TABLE 1. PICO format

\begin{tabular}{ll|}
$\begin{array}{l}\text { Population } \\
\text { Intervention }\end{array}$ & $\begin{array}{l}\text { Patients with early to moderate peri-implantitis [26] (based on case definitions, inclusion, and exclusion criteria) } \\
\text { Local drug delivery of tetracycline group of drugs (in any form: gels, fibers, irrigating agents, or nano-particles) as an adjunct to } \\
\text { non-surgical mechanical debridement of peri-implantitis sites }\end{array}$ \\
\hline \multirow{2}{*}{$\begin{array}{l}\text { Comparison } \\
\text { Outcomes }\end{array}$} & Non-surgical mechanical debridement \\
\hline
\end{tabular}


Three reviewers participated in the preliminary search strategy. After the primary search, relevant studies based on the titles and abstracts were reviewed independently by all three reviewers. Full copies of randomized controlled clinical trials, which met the inclusion criteria were evaluated rigorously for further steps. In this manner, only full-text papers were evaluated separately, and the quality of assessment and decision to include or exclude from the study reached by a mutual discussion. Studies, which did not meet the inclusion criteria were excluded, based on reasons for exclusion depicted in Table 2.

\section{DATA EXTRACTION AND MANAGEMENT}

All three reviewers participated in data collection, and included the following:

1. Type of intervention: LDD of tetracycline group of drugs in any form (fibre, gel, chips, and nanoparticles) at peri-implantitis sites along with nonsurgical periodontal treatment (supragingival scaling, subgingival scaling and peri-implant debridement).

2. Control: Non-surgical peri-implant therapy (mechanical debridement).

3. Outcome measures: Improvement in clinical attachment level and decrease in probing pocket depth, gingival bleeding, and improved gingival status.

TABLE 2. Studies excluded in the second phase of selection and reasons for exclusion

\begin{tabular}{l}
$\begin{array}{l}\text { Excluded study } \\
\text { (authors, publication } \\
\text { year [ref.]) }\end{array}$ \\
\hline Mombelli et al. 2000 [21]
\end{tabular}

During primary assortment, the titles and abstracts were screened and evaluated based on definitive inclusion criteria. Studies with patients having at least one osseointegrated implant diagnosed with peri-implantitis, with pocket depth more than or equal to $4 \mathrm{~mm}$ were included. The peer-reviewed, prospective, randomized-controlled clinical trials (RCT) published in English only were selected. The inclusion criteria for the study selection were as follows: studies evaluating the effectiveness of tetracyclines as an LDD agent in the management of peri-implantitis as compared with the non-surgical peri-implant therapy, having at least five patients in respective groups, with a minimum follow-up period of three months (Tables 3 and 4; Figure 1).

Previously treated cases of peri-implantitis (i.e., twelve months before the commencement of the study) or the use of antimicrobial agents in any form before the start of the study were criteria for exclusion. Studies with patients who had endured radiotherapy in the head and neck area, or had an incomplete or inadequate periodontal treatment before placement of dental implants, and those with uncontrolled systemic conditions were also excluded. Similarly, non-randomized trials and case reports as well as papers with uncertain case definitions were additionally excluded.

Eventually, appropriate randomized controlled clinical trials taken from both the electronic and manual search were scanned. Each article was scored based on details, such as calculation of sample size, selection of participants, allocation concealment, inclusion and exclusion criteria, blinding, and randomization for assessing the bias (Table 5).

\section{RESULTS}

The electronic databases, Pub Med, Scopus, and Cochrane Library, generated 813 potentially related titles and abstracts, while the manual search did not retrieve any additional papers. Subsequently, after the first stage

TABLE 3. Details of the selected articles

\begin{tabular}{|c|c|c|c|c|c|c|c|}
\hline \multirow{2}{*}{$\begin{array}{l}\text { Author, } \\
\text { (publication } \\
\text { year) [ref.] }\end{array}$} & \multirow[t]{2}{*}{ Study design } & \multirow[t]{2}{*}{ Implant type } & \multicolumn{2}{|c|}{$\begin{array}{l}\text { Participants/implants } \\
\text { at baseline }\end{array}$} & \multirow{2}{*}{$\begin{array}{l}\text { Procedure } \\
\text { in experimental } \\
\text { group }\end{array}$} & \multirow[t]{2}{*}{$\begin{array}{l}\text { Procedure } \\
\text { in control group }\end{array}$} & \multirow{2}{*}{$\begin{array}{c}\text { Mean } \\
\text { follow-up } \\
\text { (months) }\end{array}$} \\
\hline & & & Test $(t)$ & Control (c) & & & \\
\hline \multirow{2}{*}{$\begin{array}{l}\text { Buchter et al. } \\
\text { (2004) [22] }\end{array}$} & \multirow{2}{*}{$\begin{array}{l}\text { A randomized } \\
\text { controlled trial }\end{array}$} & \multirow{2}{*}{$\begin{array}{c}\text { ITI, SLA } \\
\text { (Straumann, } \\
\text { Freiburg, Germany) }\end{array}$} & \multicolumn{2}{|c|}{28 participants, 48 defects } & \multirow{2}{*}{$\begin{array}{l}\text { Subgingival scaling } \\
+8.5 \% \text { doxycycline } \\
\text { (atridox) }\end{array}$} & \multirow{2}{*}{$\begin{array}{c}\text { Subgingival local } \\
\text { debridement }\end{array}$} & \multirow[t]{2}{*}{4} \\
\hline & & & $t-14$ & $c-14$ & & & \\
\hline \multirow{2}{*}{$\begin{array}{l}\text { Renvert et al. } \\
\text { (2006) [23] }\end{array}$} & \multirow{2}{*}{$\begin{array}{l}\text { A randomized } \\
\text { clinical trial }\end{array}$} & \multirow{2}{*}{$\begin{array}{l}\text { Brane-mark } \\
\text { implants }\end{array}$} & \multicolumn{2}{|c|}{32 participants } & \multirow{2}{*}{$\begin{array}{l}\text { Non-surgical } \\
\text { periodontal therapy } \\
+ \text { minocycline } \\
\text { microsphere (arestin) }\end{array}$} & \multirow{2}{*}{$\begin{array}{l}\text { Non-surgical } \\
\text { periodontal therapy } \\
+ \text { chlorhexidine }\end{array}$} & \multirow[t]{2}{*}{12} \\
\hline & & & $t-16$ & $c-14$ & & & \\
\hline \multirow{2}{*}{$\begin{array}{l}\text { Renvert et al. } \\
\text { (2008) [6] }\end{array}$} & \multirow{2}{*}{$\begin{array}{l}\text { A randomized } \\
\text { clinical trial }\end{array}$} & \multirow[t]{2}{*}{ Nobel-Biocare } & \multicolumn{2}{|c|}{32 participants } & \multirow{2}{*}{$\begin{array}{l}\text { Non-surgical } \\
\text { periodontal therapy } \\
\text { + minocycline } \\
\text { microspheres }\end{array}$} & \multirow{2}{*}{$\begin{array}{c}\text { Non-surgical } \\
\text { periodontal therapy } \\
+1 \% \text { chlorhexidine } \\
\text { gel }\end{array}$} & \multirow[t]{2}{*}{12} \\
\hline & & & $t-17$ & $c-15$ & & & \\
\hline
\end{tabular}


TABLE 4. Key results of the selected studies

\begin{tabular}{|c|c|c|c|c|c|c|}
\hline $\begin{array}{l}\text { Author, (publication } \\
\text { year) [ref.] }\end{array}$ & $\begin{array}{l}\text { Implant } \\
\text { survival rate }\end{array}$ & $\begin{array}{l}\text { Probing pocket depth } \\
\text { (mm) }\end{array}$ & $\begin{array}{c}\text { Clinical attachment } \\
\text { level (mm) }\end{array}$ & $\begin{array}{l}\text { Bleeding on } \\
\text { probing (\%) }\end{array}$ & Bone loss & Comments \\
\hline $\begin{array}{l}\text { Buchter et al. (2004) } \\
\text { [22] }\end{array}$ & $\begin{array}{l}\text { Not clearly } \\
\text { reported }\end{array}$ & $\begin{array}{c}\text { Control: } \\
\text { Baseline: } 5.68 \pm 0.28 \\
\text { Four months: } 5.4 \pm 0.34 \\
\text { Experiment: } \\
\text { Baseline: } 5.64 \pm 0.32 \\
4 \text { months: } 4.49 \pm 0.29\end{array}$ & $\begin{array}{c}\text { Control: } \\
\text { Baseline: } 5.51 \pm 0.27 \\
4 \text { months: } 5.18 \pm 0.33 \\
\text { Experiment: } \\
\text { Baseline: } 5.32 \pm 0.33 \\
4 \text { months: } 4.17 \pm 0.30\end{array}$ & $\begin{array}{c}\text { Control: } \\
\text { Baseline: } 0.63 \pm 0.06 \\
4 \text { months: } 0.50 \pm 0.07 \\
\text { Experiment: } \\
\text { Baseline: } 0.54 \pm 0.07 \\
4 \text { months: } 0.27 \pm 0.06\end{array}$ & $\begin{array}{l}\text { Not } \\
\text { reported }\end{array}$ & $\begin{array}{c}4 \text { pts. were } \\
\text { current smokers } \\
\text { and } 5 \text { were } \\
\text { former smokers }\end{array}$ \\
\hline $\begin{array}{l}\text { Renvert et al. (2006) } \\
\text { [23] }\end{array}$ & $\begin{array}{l}\text { Not clearly } \\
\text { reported }\end{array}$ & $\begin{array}{c}\text { Control: } \\
\text { Baseline: } 5.1 \pm 0.5 \\
12 \text { months: } 4.9 \pm 0.6 \\
\text { Experiment: } \\
\text { Baseline: } 5.0 \pm 0.9 \\
12 \text { months: } 4.4 \pm 0.7\end{array}$ & - & $\begin{array}{c}\text { Control: } \\
\text { Baseline: } 100 \pm 0 \\
12 \text { months: } 100 \pm 0 \\
\text { Experiment: } \\
\text { Baseline: } 100 \pm 0 \\
12 \text { months: } 86 \pm 23\end{array}$ & $\begin{array}{l}\text { Not more } \\
\text { than three } \\
\text { threads } \\
\text { of implant }\end{array}$ & $\begin{array}{l}\text { No report on } \\
\text { smoking status } \\
\text { of patients }\end{array}$ \\
\hline $\begin{array}{l}\text { Renvert et al. (2008) } \\
\text { [6] }\end{array}$ & $\begin{array}{l}\text { Not clearly } \\
\text { reported }\end{array}$ & $\begin{array}{c}\text { Control: } \\
\text { Baseline: } 4.97 \pm 0.87 \\
12 \text { months: } 4.54 \pm 0.84 \\
\text { Experiment: } \\
\text { Baseline: } 4.76 \pm 0.73 \\
12 \text { months: } 4.19 \pm 0.96\end{array}$ & - & $\begin{array}{c}\text { Control: } \\
\text { Baseline: } 100 \pm 0 \\
12 \text { months: } 89 \pm 31.5 \\
\text { Experiment: } \\
\text { Baseline: } 100 \pm 0 \\
12 \text { months: } 74 \pm 44.2\end{array}$ & $\begin{array}{l}\text { Up to } \\
1.8 \mathrm{~mm}\end{array}$ & $\begin{array}{l}\text { No report on } \\
\text { smoking status } \\
\text { of patients }\end{array}$ \\
\hline
\end{tabular}

of the assessment, 546 articles were excluded based on the information obtained from titles and abstracts. We also excluded about 210 literature review papers and 45 papers that were not in English. In total, seven papers were selected and were thoroughly examined for text in the next phase. This procedure filtered four articles [18-21] based on specific exclusion criteria (Table 2). The final stage of examination selected three papers only $[6,22,23]$, which fulfilled the inclusion criteria (Tables 3 and 4).

\section{META-ANALYSIS OF STUDIES INCLUDED}

For the continuous outcomes, the mean difference was computed as the effect measure. The effect measure was plotted by meta-analysis using a random-effects model. The statistical heterogeneity was assessed by $\chi^{2}$ statistics and $I^{2}$ statistics. $\chi^{2}$ with a $p$-value $<0.1$ was considered as the presence of statistically significant presence of heterogeneity or $I^{2}>60 \%$ denoted the presence of a considerable amount of statistical heterogeneity. Moreover, Egger's test determined any publication bias.

Studies included for the present meta-analysis are shown in Table 6 . The only parameter, which could be used was "probing pocket depth", while the other parameter "clinical attachment level" was not provided in all the studies. The standard deviation given for "bleeding on probing" was \pm 100 , which was not appropriate for the meta-analysis (Table 6).

From the meta-analysis, we could observe that the pooled SMD (standardized mean difference) was -1.31 , and the $p$-value was 0.046 , which was less than the level of significance $\alpha=0.05$. Therefore, we could conclude that there was a significant difference between

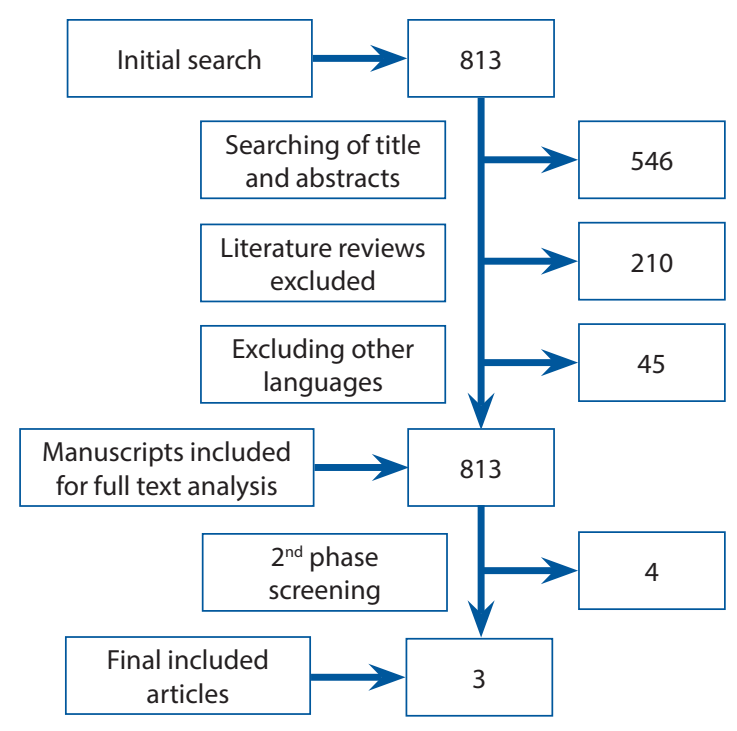

FIGURE 1. Schematic diagram of the screening and selecting the studies

the experimental and the control group. The $p$-value for heterogeneity between the studies was $0.000(p<0.001)$, suggesting dissimilarity between the studies (Figure 2 ).

\section{DISCUSSION}

Although peri-implantitis is a multifactorial disease, microbial role in initiation and progression of the disease is well-known. Therefore, incorporating antimicrobial agents as adjuvants into conventional peri-implant therapy, provide a practical and meaningful strategy to handle the disease. 
TABLE 5. Quality assessment

\begin{tabular}{|c|c|c|c|c|c|c|c|}
\hline Author, year & a & b & c & d & e & f & g \\
\hline Butcher et al., 2004 & 0 & 3 & 0 & 0 & 2 & 2 & 2 \\
\hline Renvert et al., 2006 & 0 & 3 & 1 & 1 & 1 & 2 & 2 \\
\hline Renvert et al., 2008 & 0 & 3 & 1 & 0 & 1 & 2 & 2 \\
\hline \multicolumn{8}{|c|}{ The details of category of assessment and scoring: } \\
\hline \multicolumn{8}{|c|}{$\begin{array}{l}\text { a) The sample size calculation approximates the least number of individuals mandatory to notice a significant variance amongst the groups. } \\
\text { : Not stated } \\
\text { 1: Stated, but unconfirmed } \\
\text { 2: Described and confirmed }\end{array}$} \\
\hline \multicolumn{8}{|c|}{$\begin{array}{l}\text { b) The sample size calculation approximates the least number of individuals mandatory to notice a significant variance amongst the groups. } \\
0 \text { : Not stated } \\
\text { 1: Stated, but unconfirmed } \\
\text { 2: Described and confirmed }\end{array}$} \\
\hline \multicolumn{8}{|c|}{$\begin{array}{l}\text { c) Method of randomization and allocation concealment } \\
0 \text { : Not stated } \\
\text { 1: Undoubtedly insufficient } \\
\text { 2: Probably sufficient: there could be a potential chance of bias } \\
\text { 3: Undoubtedly sufficient }\end{array}$} \\
\hline \multicolumn{8}{|c|}{$\begin{array}{l}\text { d) Distinct characterization of inclusion and exclusion criteria } \\
0: \text { No } \\
1: \text { Yes }\end{array}$} \\
\hline \multicolumn{8}{|l|}{$\begin{array}{l}\text { e) Dropouts } \\
0: \text { Not stated } \\
1: \text { Clearly stated }\end{array}$} \\
\hline \multicolumn{8}{|c|}{$\begin{array}{l}\text { f) Whether the test and control groups analogous at baseline regarding the confounding factors } \\
0 \text { : Not stated } \\
\text { 1: Uncertain/probably not comparable regarding few confounding factors } \\
\text { 2: Yes, all groups were similar at baseline }\end{array}$} \\
\hline $\begin{array}{l}\text { g) Blinding } \\
\text { 0: Blinding not carr } \\
\text { 1: Not mentioned } \\
\text { 2: Yes, blinding wa }\end{array}$ & mas & & & & & & \\
\hline
\end{tabular}

TABLE 6. Meta-analysis of probing pocket depths

\begin{tabular}{|l|c|c|c|c|c|c|c|}
\hline & \multicolumn{3}{c}{ Experimental group } & \multicolumn{3}{c}{ Control group } & \multicolumn{2}{c|}{ Sp } \\
\hline & Mean1 & SD1 & n1 & Meano & SD0 & \\
\hline Buchter et al., 2004 & 4.49 & 0.29 & 28 & 5.40 & 0.34 & 28 & 0.096 \\
\hline Renvert et al., 2006 & 4.40 & 0.70 & 32 & 4.9 & 0.60 & 32 & 0.411 \\
\hline Renvert et al., 2008 & 4.19 & 0.96 & 32 & 4.54 & 0.84 & 32 & 0.780 \\
\hline
\end{tabular}

Initially, we obtained 813 possibly relevant papers. However, only three were decided for the meta-analysis, as other papers did not meet the inclusion criteria. Clinical, radiographic, and microbial parameters determined the success of peri-implant therapy. The clinical parameters included clinical attachment level, probing depth, bleeding on probing, implant mobility, and gingival inflammation. The radiographic parameters comprised intraoral peri-apical radiographs at regular intervals to assess bone gain. The subgingival microbial load also provided additional information about the changes in the disease state during the treatment.

In the present study, we focused on the available studies, which aimed to evaluate the effectiveness of the tetracycline group of drugs dispensed as local delivery formulations in the treatment of peri-implantitis. The usage of antimicrobial agents was based on the rationale that most of the implant failures occurred due to re-colonizing of microbes, which provoked the host inflammatory/immune response causing tissue destruction, eventually leading to loss of osseo-integration [5]. Therefore, the primary objective of treating periimplantitis would be to decrease the number of microorganisms, achieve a state of health of peri-implant, and most likely, restore the peri-implant bone loss attributed to inflammation.

The non-surgical treatment of peri-implantitis is an effective method for biofilm disruption and removal [24]. 
Non-surgical treatment efficacy could not be assessed using a true outcome measure, because no included study reported implant survival rate. In the present metaanalysis, we only focused on studies that evaluated locally delivered tetracycline group of drugs and excluded those with systemic routes of administration. We selected the tetracycline-group because of their broad antimicrobial and anti-collagenase potential. Till date, no systematic reviews or meta-analyses have addressed the role of tetracycline in peri-implantitis.

The studies included in the present analysis concerned the non-surgical peri-implant mechanical debridement alone, or with any tetracycline drug group. All the studies reported probing pocket depth and bleeding on probing at baseline and after completing the study. The probing pocket depth was the only clinical parameter, which was consistent in the three selected studies. Apart from this, Buchter et al. [22] reported clinical attachment levels (CAL). However, CAL was not mentioned in the other two studies, and therefore could not be used for the metaanalysis. The microbial load was assessed by Renvert et al. in 2006 [23] and in 2008 [6], but not by Buchter et al. [22]. Furthermore, radiographic interpretation was lacking in all three studies.

The mean yearly rate of bone loss around untreated case of peri-implantitis was $0.15 \mathrm{~mm}$ [25]. Fransson et al. suggested that the development of peri-implantitis-related bone loss was time-dependent [26]. Both studies by Renvert et al. $[6,23]$ assessed the adjunctive use of antibiotics with non-surgical mechanical debridement of periimplantitis. And both the studies showed a similar effect using minocycline microspheres (Minocycline, Arestin, Ora-Pharma Inc., Warminster, PA, USA) as compared to chlorhexidine. The improvement in peri-implant probing depth persisted for up to 12 months. Furthermore, the authors mentioned that bone loss was present in no more than three implant threads. Hence, the role of minocycline in peri-implantitis cases with greater severity (more than three implant threads) remains to be clarified $[6,23]$.

The exclusion criteria amongst the selected papers were relatively homogenous. All the studies excluded patients who were using antibiotics 3-6 months before the study enrollment, and those who were pregnant and lactating [6, 22, 23]. Although Buchter et al. [22] did not report clear exclusion criteria, they did consider active smokers. In contrast, other studies did not mention the smoking status of subjects. Bone loss exceeding $1.8 \mathrm{~mm}$ was a criterion for exclusion in the study by Renvert et al. [23]. Buchter et al. [22] did not mention the features associated with the implant design, such as hollow cylinders and thread design. However, Renvert et al. $[6,23]$ reported the use of Branemark implants.

Buchter's study compared non-surgical peri-implant debridement used alone and as an addition to LDD with doxycycline. In the two studies by Renvert et al., $1 \%$ chlorhexidine gel with non-surgical peri-implant debridement was used as an adjunct to LDD of mino-

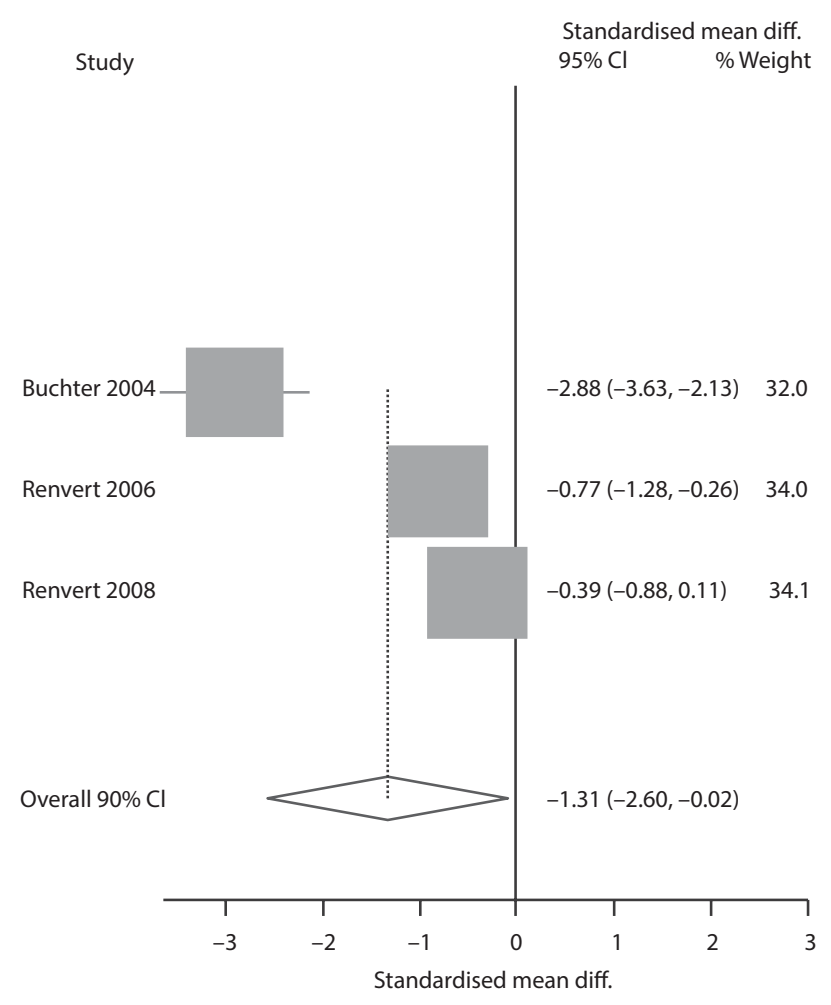

FIGURE 2. The depiction of probing pocket depth in the forest plot

cycline microspheres. Additionally, the observation periods ranged from 4 to 12 months. The studies under consideration did not report adverse effects neither withdrawal of subjects from the trials.

Renvert et al. $[6,23]$ reported the conduct of microbiological analyses in their studies. Both the studies had low levels of the total viable count at the beginning of the study, which would explain why it remained relatively similar towards the end. It was essential to inspect one or more of the following species of periodontal pathogens, including Porphyromonas gingivalis, Prevotella intermedia, Prevotella nigrescens, and Tannerella forsythia in the selected subjects. There was no variance observed in the mean total statistics of microbes within the treatment groups at individual or implant levels. Fusobacterium nucleatum showed a minor upsurge over time, which was insignificant at the implant level and the subject level for both treatments; although an additional five bacterial species were portrayed to show a slight reduction over time. None of these variations was important. The mean total viable count at the individual level and implant level was not statistically significant at any given time.

Maintenance care and recall intervals during the follow-up phase of the trials also varied. The follow-up period of the selected studies ranged from 4 to 12 months. Furthermore, the regularity of continuous care throughout the follow-up phase of the trials was erratic and unreliable. While Buchter et al. [22] specified the reinforce- 
ment of oral hygiene measures every week, the other studies did not indicate oral hygiene habits and maintenance phase recall. The number of patients included was comparatively small, resulting in low statistical power for distinguishing actual variance between treatments. Therefore, larger clinical trials with long-term followup are required to assess the clinical benefits of tetracycline as an adjuvant to non-surgical treatment of periimplantitis.

Our systematic review was in line with a previously performed meta-analysis that showed a significant improvement in periodontal parameters, such as CAL, $\mathrm{PD}$, and sulcular bleeding index, and favored the use of tetracyclines in the form of local drug delivery [16].

The current systematic review highlights the limitations of the available literature concerning the occurrence, degree and extent of peri-implantitis. The investigated studies also used convenience sampling method, with limited samples sizes. The diversity of case explanation and characterization demonstrated the nonexistence of agreement in the investigation. While all included papers have used the definitions for periimplant diseases as previously recommended, they varied significantly. Different disease thresholds had a different impact on the frequency of disease incidence $[5,27]$.

There is understandable necessity for consensus in relating to disease thresholds to ease comparisons. Sanz and Chapple suggested case definitions at the $8^{\text {th }}$ European Workshop on Periodontology for future periimplantitis epidemiological investigations to identify onset and severity of peri-implant disease [28]. Zitzmann and Berglundh recommended epidemiological studies on peri-implantitis, including not only prevalence or incidence of disease but also its extent and severity. The prevalence and severity of peri-implant diseases were rarely reported [5]. We recommend that studies should apply case definitions [28] suggested by consensus conferences and should define the severity of disease by grouping peri-implantitis-affected implants according to the degree of bone loss.

\section{CONCLUSIONS}

Based on the observations made from the systematic review and meta-analysis, we observed that the local delivery of tetracycline group of drugs has shown signs of clinical improvement in cases of peri-implantitis, when used as an adjuvant to mechanical debridement. However, these results are not statistically significant. Henceforth, prospective studies on peri-implant disease management could consider application of recommended case definitions, adopt random selection, and patient-allocation based on appropriate sample sizes. In our opinion, specific clinical outcome measures with criteria to evaluate the improvement of function as well as long-term follow up would generate additional evidence to assist clinical decision-making on the use of locally delivered tetracycline group of drugs in the treatment of peri-implantitis.

\section{CONFLICT OF INTEREST}

The authors declare no potential conflicts of interest with respect to the research, authorship, and/or publication of this article.

\section{References}

1. Simonis P, Dufour T, Tenenbaum H. Long-term implant survival and success: a 10-16-year follow-up of non-submerged dental implants. Clin Oral Implants Res 2010; 21: 772-777.

2. Sakka S, Baroudi K, Nassani MZ. Factors associated with early and late failure of dental implants. J Investig Clin Dent 2012; 3: 258-261.

3. Prashanti E, Sajjan S, Reddy JM. Failures in implants. Indian J Dent Res 2011; 22: 446-453.

4. Mombelli A, Van Oosten MA, Schürch Jr E, Lang NP. The microbiota associated with successful or failing osseointegrated titanium implants. Oral Microbiol Immunol 1987; 2: 145-151.

5. Zitzmann NU, Berglundh T. Definition and prevalence of periimplant diseases. J Clin Periodontol 2008; 35: 286-291.

6. Renvert S, Lessem J, Dahlén G, Renvert H, Lindahl C. Mechani$\mathrm{cal}$ and repeated antimicrobial therapy using a local drug delivery system in the treatment of peri-implantitis: a randomized clinical trial. J Periodontol 2008; 79: 836-844.

7. Rajeswari HR, Dhamecha D, Jagwani S, Rao M, Jadhav K, Shaikh S, Puzhankara L, Jalalpure S. Local drug delivery systems in the management of periodontitis: a scientific review. J Control Release 2019; 307: 393-409.

8. Ata-Ali J, Candel-Marti ME, Flichy-Fernández AJ, PeñarrochaOltra D, Balaguer Martinez JF, Peñarrocha Diago M. Peri-implantitis: associated microbiota and treatment. Med Oral Patol Oral Cir Bucal 2011; 16: e937-943.

9. Heitz-Mayfield LJ, Mombelli A. The therapy of peri-implantitis: a systematic review. Int J Oral Maxillofac Implants. 2014; 29 Suppl: 325-345.

10. Karring ES, Stavropoulos A, Ellegaard B, Karring T. Treatment of peri-implantitis by the Vector system. Clin Oral Implants Res 2005; 16: 288-293.

11. Sahm N, Becker J, Santel T, Schwarz F. Non-surgical treatment of peri-implantitis using an air-abrasive device or mechanical debridement and local application of chlorhexidine: a prospective, randomized, controlled clinical study. J Clin Periodontol 2011; 38: 872-878.

12. Mombelli A, Feloutzis A, Brägger U, Lang NP. Treatment of periimplantitis by local delivery of tetracycline. Clinical, microbiological and radiological results. Clin Oral Implants Res 2001; 12: 287-294.

13. Goodson JM, Offenbacher S, Farr DH, Hogan PE. Periodontal disease treatment by local drug delivery. J Periodontol 1985; 56: 265-272.

14. Gu Y, Walker C, Ryan ME, Payne JB, Golub LM. Non-antibacterial tetracycline formulations: clinical applications in dentistry and medicine. J Oral Microbiol 2012; 4: 19227.

15. Chopra I, Roberts M. Tetracycline antibiotics: mode of action, applications, molecular biology, and epidemiology of bacterial resistance. Microbiol Mol Biol Rev 2001; 65: 232-260.

16. Nadig PS, Shah MA. Tetracycline as local drug delivery in treatment of chronic periodontitis: A systematic review and metaanalysis. J Indian Soc Periodontol 2016; 20: 576-583.

17. Miller SA, Forrest JL. Enhancing your practise through evidencebased decision making: PICO, learning how to ask good questions. J Evid Based Dent Pract 2001; 1: 136-141. 
18. Salvi GE, Persson GR, Heitz-Mayfield LJ, Frei M, Lang NP. Adjunctive local antibiotic therapy in the treatment of periimplantitis II: clinical and radiographic outcomes. Clin Oral Implants Res 2007; 18: 281-285.

19. Persson GR, Salvi GE, Heitz-Mayfield LJ, Lang NP. Antimicrobial therapy using a local drug delivery system (Arestin) in the treatment of peri-implantitis. I: Microbiological outcomes. Clin Oral Implants Res 2006; 17: 386-393.

20. Heo S, Kim HJ, Joo JY, Lee J, Kim SJ, Choi J. Simplified non-surgical treatment of periimplantitis using chlorhexidine and minocycline hydrochloride. J Periodontal Implant Sci 2018; 48: 326-333.

21. Mombelli A. Microbiology and antimicrobial therapy of periimplantitis. Periodontol 2000 2002; 28: 177-189.

22. Büchter A, Meyer U, Kruse-Lösler B, Joos U, Kleinheinz J. Sustained release of doxycycline for the treatment of peri-implantitis: randomized, controlled trial. Br J Oral Maxillofac Surg 2004; 42 439-444.

23. Renvert S, Lessem J, Dahlén G, Lindahl C, Svensson M. Topical minocycline microspheres versus topical chlorhexidine gel as an adjunct to mechanical debridement of incipient peri-implant infections: a randomized clinical trial. J Clin Periodontol 2006 33: $362-369$

24. Schwarz F, Schmucker A, Becker J. Efficacy of alternative or adjunctive measures to conventional treatment of peri-implant mucositis and peri-implantitis: a systematic review and meta-analysis. Int J Implant Dent 2015; 1: 22

25. Cecchinato D, Parpaiola A, Lindhe J. A cross-sectional study on the prevalence of marginal bone loss among implant patients. Clin Oral Implants Res 2013; 24: 87-90.

26. Fransson C, Lekholm U, Jemt T, Berglundh T. Prevalence of subjects with progressive bone loss at implants. Clin Oral Implants Res 2005; 16: 440-446.

27. Renvert S, Polyzois IN. Clinical approaches to treat peri-implant mucositis and periimplantitis. Periodontol 2000 2015; 68: 369-404.

28. Sanz M, Chapple IL. Clinical research on peri-implant diseases: Consensus report of Working Group 4. J Clin Periodontol 2012, 39 (Suppl 12): 202-206. 
